\title{
Controlled reperfusion
}

\author{
Hajime Ichikawa, MD, PhD
}

Received: 29 April 2011

(C) The Japanese Association for Thoracic Surgery 2012

Myocardial protection during cardiac surgery in adults has become close to satisfactory since blood cardioplegia and controlled reperfusion with terminal warm blood cardioplegia were introduced in the clinical setting. ${ }^{1}$ However, in the field of congenital heart surgery, there is still a demand for a better modality for myocardial protection during some highly complex repairs that require a long cross-clamp time. Another rationale for developing a better modality is simply the vulnerability of neonatal myocardium.

Kinouchi et al. performed an interesting experiment using 4-week-old piglets, mimicking a clinical situation in pediatric cardiac surgery. They investigated the beneficial effects of olprinone in terminal warm blood cardioplegia, which is potentially applicable to the clinical situation.

Historically, the concept of controlled reperfusion started during the mid-1970s. ${ }^{2}$ The first generation of controlled reperfusion was targeted to alter the ion concentrations (i.e., calcium, potassium, and $\mathrm{pH}$ of the reperfusate) during reperfusion. Numerous articles have described the beneficial effects of controlled reperfusion. The most promising situation was acidic reperfusion achieved simply by temporarily lowering the $\mathrm{pH}$ of the reperfusate. $^{3-5}$ The effect of acidic reperfusion is to sup-

This editorial refers to the article by Kinouchi et al. on pp. 73-81 of this issue of General Thoracic and Cardiovascular Surgery.

H. Ichikawa $(\bowtie)$

Department of Pediatric Cardiovascular Surgery, National Cerebral and Cardiovascular Center, 5-7-1 Fujishiro-dai, Suita, Osaka 565-8565, Japan

Tel. +81-6-6833-5012; Fax +81-6-6833-9865

e-mail: ichikawa@hsp.ncvc.go.jp press $\mathrm{Na} / \mathrm{H}$ exchange during the reperfusion, thereby preventing sodium accumulation during the early reperfusion period, when the $\mathrm{Na} / \mathrm{K}$ pump has not started to work. Acidic reperfusion may also reduce oxygen consumption during the early reperfusion phase simply by suppressing contractions. Although most experimental studies showed a significantly beneficial effect of acidic reperfusion, no major clinical study has yet been performed. Lowering calcium in the reperfusate is controversial because lowering the extracellular calcium level may allow $\mathrm{Na}$ overload via the $\mathrm{Na}-\mathrm{Ca}$ exchange mechanism.

The effects of terminal warm blood cardioplegia were first reported by Teoh et al. ${ }^{1}$ in 1986. Since then, the use of terminal warm blood cardioplegia became popular for operations in patients known to have impaired myocardium. This beneficial effect seems to be due mainly to the following the mechanism. The terminal blood cardioplegia restores energy production by supplying a substitute (i.e. oxygen, glucose) while high extracellular potassium suppresses the initiation of action potentials, hence saving energy consumption. Therefore, the heart can restore the oxygen and energy debt burdened during the period of ischemia.

There are other benefits of controlled reperfusion. In the clinical setting, terminal blood cardioplegia is usually delivered with constant flow but not constant pressure. The excess coronary flow induced by the reactive hyperemia that occurs immediately after ischemia may cause endothelial dysfunction of the coronary arteries. This can be avoided by constant-flow reperfusion with terminal cardioplegia, which delivers oxygen and substrates.

Other candidates to be controlled during reperfusion are free radical species. Because a major portion of reperfusion injury is thought to be triggered by the 
induction of oxygen radical species, free radical scavengers or leukocyte depletion at the initiation of reperfusion may have beneficial effects. Leukocyte-depleted terminal warm blood cardioplegia was thus adopted in the clinical setting and proved to be effective. ${ }^{6}$

The main purpose of the study by Kinouchi et al. in this issue was to prove the beneficial effect of adding phosphodiesterase (PDE) III inhibitor to terminal warm blood cardioplegia. Using the same animal model, this was already proved by the author's group ${ }^{7}$ but using amrinone instead of olprinone. As amrinone is not available to the clinical setting in Japan, it is worthwhile publishing their results with olprinone, which is widely available in Japan.

The terminal warm blood cardioplegia used in the present experiment contains a relatively low concentration of calcium. The optimal calcium concentration in the cardioplegia varies depending on the type of cardioplegia, the temperature, and the potassium concentration. The calcium concentration the authors employed in the present experiment is on the modest side $(0.54 \pm$ $0.03 \mathrm{mmol} / \mathrm{l})$. It is not very high or very low and probably does no harm and offers no benefit. It also cannot affect the action of the PDE inhibitor.

The mechanism of the protective properties of the PDE inhibitor is unclear. The authors cited the work by Sanada et al., who demonstrated the myocardial protective effect of PDE inhibitors. The mechanism in the present article might be different, however, because the experiments by Sanada et al. showed that PDE III inhibitors given before the induction of ischemia enhanced ischemic tolerance (decreased the infarct size) possibly through ischemic preconditioning.

PDE III inhibitors, including olprinone, increase cyclic AMP and hence increase the contractility of the myocardium; they also have the potential to relax vascular smooth muscle, causing vasodilation. If a PDE III inhibitor is infused along with a high-concentration potassium solution into the coronary artery system, the effect would be only vasodilation because the heart is arrested by extreme depolarization. The harmful vasoconstrictive effect of high potassium could be canceled by the PDE III inhibitor. Although terminal warm blood cardioplegia was undertaken with a constant infusion speed in the present experiments, there was, unfortunately, no information about the infusion pressure in the coronary arterial system when it was given.

During the 1990s, several studies reported that preischemic administration of PDE III inhibitor was harmful when using a whole heart ischemic model in isolated rat heart experiments. ${ }^{8,9}$ One can argue that there are fundamental differences between experimental models. First, the experiment in the present study is more similar to the real clinical setting, whereas the experiments by Shimada et al. and Komai et al. were in vitro experiments. In the present study by Kinouchi et al., hearts were perfused in vivo with blood throughout the experiments. The processes that occurred during ischemia and reperfusion were more complicated and multifactorial than those in experiments where hearts were perfused with a crystalloid solution. Many factors are different, including ionic $\left(\mathrm{Na}^{+}, \mathrm{Ca}^{2+}, \mathrm{H}^{+}\right)$movements, vascular reactivity of the coronary arterial system, and free radical insult among others. Another important point is the species difference. So far, there have been no detailed experiments in which the difference in the calcium-handling systems of humans and piglets were investigated. On the other hand, the special characteristics of the rat heart have been investigated in detail. Rat hearts have a superior calcium-handling system with highly developed sarcoplasmic reticulum, which enables the rat heart to beat at a very high rate. This may, however, cause the rat heart to be vulnerable to calcium overload after reperfusion.

The concentration of olprinone at the time of cardiac functional measurements was too low to show any effect. However, one can argue that no evidence was shown that the tissue concentration of olprinone is also very low.

The decrease in Lipidperoxide (LPO) in the coronary effluent is also a good indication that the myocardial damage by free radical species is attenuated by terminal warm blood cardioplegia with olprinone. The serum LPO level continues to be suppressed even when the olprinone level is undetectable, suggesting that this protective property worked at the onset of ischemia-reperfusion injury. It is an interesting finding, and it would have been good if the authors had shown that it is a direct effect of olprinone. The magnitude of free radicalmediated myocardial insult is a function of the magnitude of the ischemia-reperfusion insult. The generation of free radicals can be attenuated by other means of myocardial protection.

The authors nicely showed that the cardiac function 30 and $60 \mathrm{~min}$ after the hearts were reperfused were improved by the addition of olprinone to the terminal warm blood cardioplegia. Clinicians must be curious what would have happened if the authors extended the time course after the reperfusion. It is important to prove that this effect is not a temporary effect and protects the heart against permanent myocardial damage. The microscopic findings of the myocardium after reperfusion are also important.

Commonly, in experiments investigating the myocardial protective properties of certain methods, the degree of ischemic insult in the control group is likely to be set at an extreme degree to show a statistically significant 
effect. As this experiment simulated clinical settings of cardiac surgery in an infant, the question arises whether the insult achieved with only 90 min of single-dose cold crystalloid cardioplegic solution is clinically relevant.

As the authors noted, there have been some articles that described the protective effects of olprinone against ischemia-reperfusion injury in organs used for transplantation. Organ preservation methods have been developed for various organs, and analogies can be made when working with these organs because there is a common purpose of the preservation (i.e., "ATP preservation"). However, the characteristic features of myocardium are different from those of liver, kidney, or pancreas because the heart is an organ consisting of excitable cells. In particular, the calcium and sodium transport systems have special mechanisms in excitable cells, as in muscle and neuronal cells. Hence, tolerance to ischemia-reperfusion is different from that of other organs. There remains a question, then, whether this analogy is valid.

The mechanism by which terminal warm blood cardioplegia preserves cyclic AMP after reperfusion may be energy restoration during controlled reperfusion without energy consumption. The authors previously showed that this preservation is enhanced by addition of amrinone. ${ }^{7}$ However, in the present experiment using olprinone, there was no significant difference. This inconsistency can be resolved by investigating the optimal dose of olprinone.

The use of olprinone for terminal cardioplegia is highly attractive especially because it is available in the clinical setting. However, because there were some opposite results ${ }^{8,9}$ with the PDE III inhibitor, as mentioned above, care should taken before using this method in humans. The proarrhythmia property of the PDE III inhibitor should also be taken into account.
I was very happy to have the opportunity to comment on this excellent work by the authors. Their series of experiments are important and should be continued to introduce a better myocardial protective method in the clinical setting.

\section{References}

1. Teoh KH, Christakis GT, Weisel RD, Fremes SE, Mickle DA, Romaschin AD, et al. Accelerated myocardial metabolic recovery with terminal warm blood cardioplegia. J Thorac Cardiovasc Surg 1986;91:888-95.

2. Follette D, Fey K, Livesay J, Maloney JV Jr, Buckberg GD. Studies on myocardial reperfusion injury. I. Favorable modification by adjusting reperfusate $\mathrm{pH}$. Surgery 1977;82:149-55.

3. Follette DM, Fey K, Buckberg GD, Helly JJ Jr, Steed DL, Foglia $\mathrm{P}$, et al. Reducing postischemic damage by temporary modification of reperfusate calcium, potassium, $\mathrm{pH}$, and osmolarity. J Thorac Cardiovasc Surg 1981;82:221-38.

4. Kitakaze M, Weisfeldt ML, Marban E. Acidosis during early reperfusion prevents myocardial stunning in perfused ferret hearts. J Clin Invest 1988;82:920-7.

5. Ibuki C, Hearse DJ, Avkiran M. Mechanisms of antifibrillatory effect of acidic reperfusion: role of perfusate bicarbonate concentration. Am J Physiol 1993;264:H783-90.

6. Sawa Y, Taniguchi K, Kadoba K, Nishimura M, Ichikawa H, Amemiya A, et al. Leukocyte depletion attenuates reperfusion injury in patients with left ventricular hypertrophy. Circulation 1996;93:1640-6.

7. Ko Y, Morita K, Nagahori R, Kinouchi K, Shinohara G, Kagawa H, et al. Myocardial cyclic AMP augmentation with high-dose PDEIII inhibitor in terminal warm blood cardioplegia. Ann Thorac Cardiovasc Surg 2009;15:311-7.

8. Shimada Y, Yamamoto F, Yamamoto H, Newling R. Is the use of catecholamine before ischemic arrest safe? Effect of catecholamine on rat heart ischemia/reperfusion injury. Jpn J Thorac Cardiovasc Surg 1999;47:299-312.

9. Komai H, Yamamoto F, Tanaka K, Ichikawa H, Shibata T, Koide A, et al. Harmful effects of inotropic agents on myocardial protection. Ann Thorac Surg 1991;52:927-33. 